\title{
A method to study cell proliferation kinetics in human gastric mucosa
}

\author{
O. HART HANSEN ${ }^{1}$, T. PEDERSEN, AND J. K. LARSEN
}

From the Department of Surgery A, Bispebjerg Hospital, and The Finsen Laboratory, The Finsen Institute, Copenhagen, Denmark

SUMMARY The purpose of this investigation was to study cell proliferation kinetics in human gastric mucosa. Biopsies were taken from the antral and fundic part of the stomach through a fibre-gastroscope and incubated in culture medium containing a DNA-precursor ( ${ }^{3} \mathrm{H}$-thymidine). Autoradiographs were prepared by the dipping technique. The number of labelled cells and the total number of cells in all cross sections of foveolae containing one or more labelled cells were counted. The labelling index (LI), which is defined as the percentage of labelled cells in the progenitor cell region, was estimated. When only cross sections with labelled cells are taken into consideration, the labelling index will be a little overestimated. In order to reduce this error a formula for correction was worked out.

Thirty-six patients with different gastric diseases were studied. The observer error was minimal, and the results were highly reproducible. It was not possible to demonstrate any correlation between the labelling indices in antral and fundic mucosa. A significantly increased epithelial proliferation was found in fundic mucosa from patients with gastric cancer and atrophic gastritis.

During the last few years autoradiographic methods have permitted appreciable progress in the understanding of cell proliferation kinetics in the mucosa of the digestive tract (Quastler and Sherman, 1959; Clarke, 1973; Lipkin, 1973). However, only a few studies have dealt with the kinetics of human gastric mucosa. Experimental investigations have elucidated the process of cell renewal in gastric mucosa in different animals (Creamer, Shorter, and Bamforth, 1961; Willems, 1972). In most of these studies the technique of autoradiography after labelling in vivo with ${ }^{3} \mathrm{H}$-thymidine was used, but good agreement has previously been demonstrated between estimates in vivo and in vitro of the kinetic parameters in dog gastric mucosa (Willems, Galand, and Chretien, 1970). Since labelling in vivo in man generally must be avoided because of ethical considerations, incubation in vitro of gastric biopsies with ${ }^{3} \mathrm{H}$-thymidine has to be used.

In the steady state, epithelial cell loss from the gastric mucosa is in equilibrium with the rate of cell production. On this basis, Croft, Pollock, and

${ }^{1}$ Correspondence should be addressed to: Ole Hart Hansen, Department of Surgery A, Bispebjerg Hospital, DK-2400 Copenhagen NV, Denmark.

Received for publication 18 September 1974.
Coghill (1966) developed a method to measure the rate of gastric DNA loss, which they used to estimate gastric cell turnover in man. The procedure has been used by other investigators (Max and Menguy, 1970; Croft and Cotton, 1973; Desai, Venugopalan, and Antia, 1973), but an assumption for its use must be that the cell proliferation kinetics are similar in the antral and fundic mucosa. Considering the secretory and histological differences between the two types of gastric mucosa, a different growth pattern may be expected.

After the introduction of fibreoptic gastroscopes, it has been easy to obtain biopsies from well defined sites in the stomach. This paper describes an autoradiographic method for the study of cell proliferation kinetics in small endoscopic biopsies. By this procedure it has been possible to compare the fraction of cells in DNA-synthesis phase (S-phase) in human antral and fundic mucosa.

\section{Material and Methods}

Thirty-six randomly selected patients were studied. There were 20 women and 16 men with ages ranging from 30 to 77 years. In all patients gastroscopy was performed in the morning, after 12 hours fasting, using a fibreoptic gastroscope (Olympus GF-BK or 
GIF-D). The endoscopic diagnosis was in six patients duodenal ulcer, in four prepyloric ulcer, in five gastric ulcer, in five gastric cancer, in six atrophic gastritis, and in 10 a normal stomach was found.

\section{BIOPSIES AND AUTORADIOGRAPHIC PROCEDURE}

Through the gastroscope two biopsies were obtained from the antral part of the stomach $(2 \mathrm{~cm}$ above the pylorus on the lesser curvature) and two from the fundic part (high on the greater curvature) in each patient. The corresponding biopsies were taken $1-2 \mathrm{~cm}$ from each other. Histologically, the biopsies included mucosa to the level of the lamina of the muscularis mucosae. The specimens were immediately incubated in a shaking water bath at $37^{\circ} \mathrm{C}$, in 5 ml of Eagle's basal medium with Hanks' salts (Flow Laboratories, Rockville, USA) containing $20 \mu \mathrm{Ci}$ per $\mathrm{ml}$ of ${ }^{3} \mathrm{H}$-thymidine (Radiochemical Centre, Amersham, England, of specific activity 22$26 \mathrm{Ci}$ per mmole). The $\mathrm{pH}$ was adjusted to $7 \cdot 3-7 \cdot 4$ with sodium bicarbonate. After incubation for 30 minutes the biopsies were washed in unlabelled medium for 10 minutes, fixed in Bouin's solution for one hour, embedded in paraffin, and serially sectioned at $4 \mu$. The slides were coated with liquid photographic emulsion (Ilford K2), exposed for two weeks at $4^{\circ} \mathrm{C}$, developed and stained with haematoxylin and eosin or by the periodic-acid-Schiff method.

\section{COUNTING PROCEDURE}

In the autoradiographs those cells which during incubation incorporated ${ }^{3} \mathbf{H}$-thymidine appeared labelled (fig 1) and were therefore considered as being in S-phase. The percentage of labelled cells in a given cell population is defined as the labelling index. Cell counts were performed only in cross sections of the foveolae.

The cells were considered labelled if they had five or more grains over the nucleus. The number of labelled cells and the total number of cells in all cross sections of foveolae containing one or more labelled cells were counted, and a mean labelling index was calculated. In all biopsies every third section was surveyed and 500 to 2000 cells were counted. In 28 biopsies cell counts were performed blindly by two investigators in order to elucidate the observer variance.

When only cross sections containing labelled cells are taken into consideration, the labelling index will be overestimated because those cross sections through the progenitor cell region, which do not have labelled cells, will not be included in the estimation. However, this error can be reduced by use of

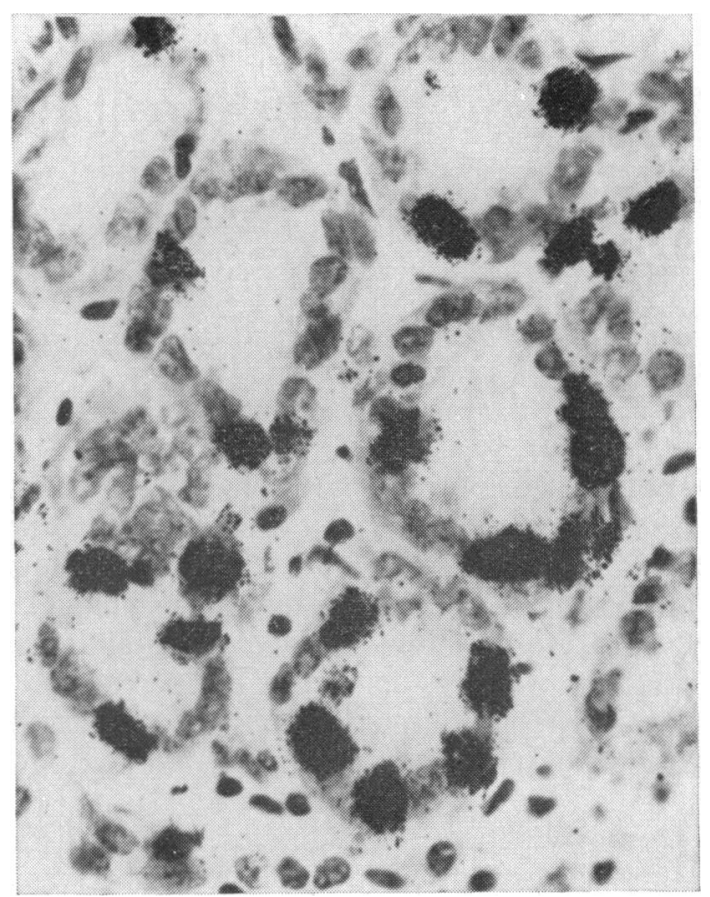

Fig 1 Light microautoradiography of human gastric mucosa. Several cells in cross sections of foveolae are labelled (haematoxylin and eosin $\times 500$ ).

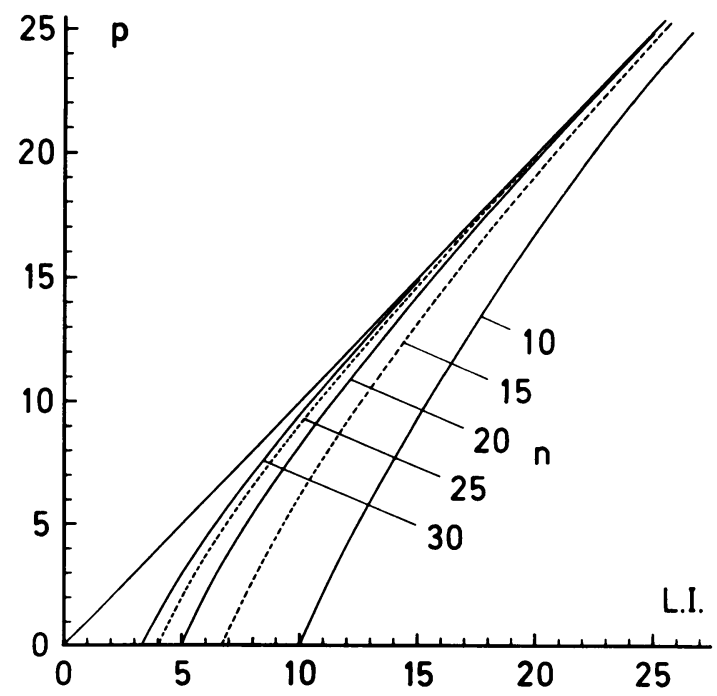

Fig 2 Nomogram for correction of labelling indices estimated on basis of cell counts in cross sections of foveolae. $\mathrm{p}$ represents the corrected labelling index, $\mathrm{n}$ the mean number of cells in the cross sections, and L.I. the actual estimated labelling index. 
the equation: $(1 \div p)^{n}=1 \div \frac{p}{L I}$, where $p$ represents

the corrected labelling index, $\mathrm{n}$ the mean number of cells in the cross sections, and LI the actual estimated labelling index. This equation was worked out on the assumption that the labelled cells are randomly distributed in the area of proliferating cells and that the number of cells in the cross sections is constant. On basis of the equation a nomogram (fig 2) was made, from which the corrected labelling index can be read, when the estimated labelling index and the mean number of cells in the examined cross sections are known.

For statistical analysis the Spearman coefficient of correlation ( $\mathrm{rsp}$ ) was calculated on the basis of the labelling index in paired biopsies.

\section{Results}

Only in $13(9 \%)$ biopsies were an insufficient number of labelled cells or cross sections of foveolae present for study. The background labelling never exceeded 0.8 grains $/ 100 \mu^{2}$. Only those cells in the lower portions of gastric pits, including neck and isthmus regions, which were labelled, supporting the view that proliferation only takes place in this part

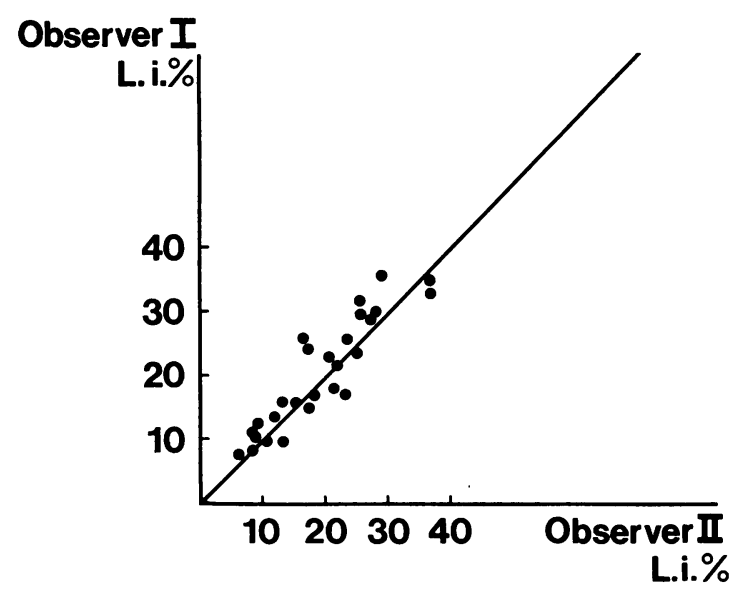

Fig 3 Observer variance $\left(n=28, r_{S P}=0.942\right.$, $\mathbf{P}<0.001)$.

of the mucosa. The results of blind examination by different observers of 28 biopsies appears in figure 3 . The observer error was found to be minimal.

In 33 patients the estimated labelling indices in corresponding biopsies from the fundic part of the stomach were compared (fig 4). The correlation between the labelling indices is highly significant $(P<0.001)$, signifying good reproducibility of the labelling index in fundic mucosa. In 26 subjects the

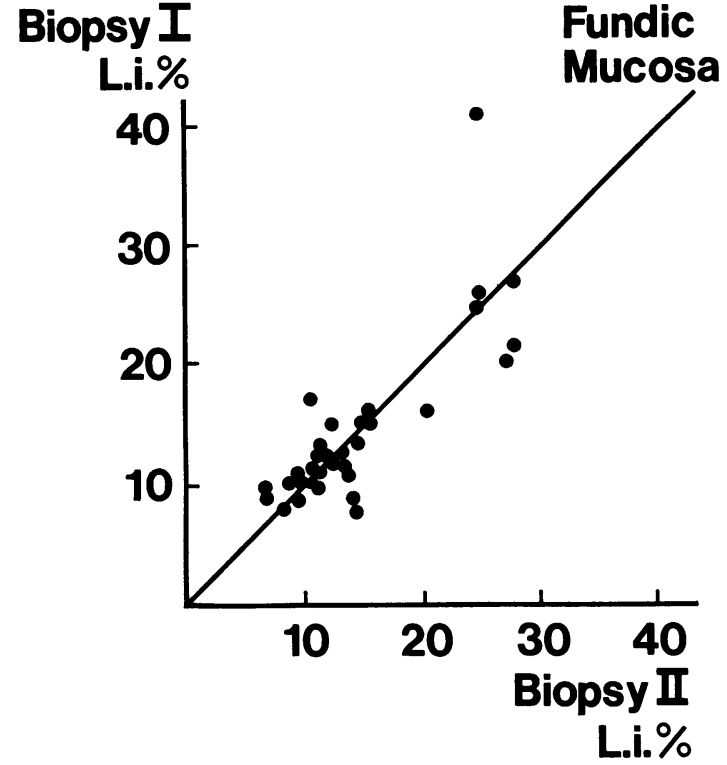

Fig 4 The correlation between labelling indices in biopsies taken near each other in the fundic part of the stomach $\left(n=33, r_{S P}=0.727, \mathrm{P}<0.001\right)$.

labelling index in corresponding biopsies from the antrum could be compared (fig 5). A highly significant correlation between the labelling indices was found $(P<0.001)$ in this site also.

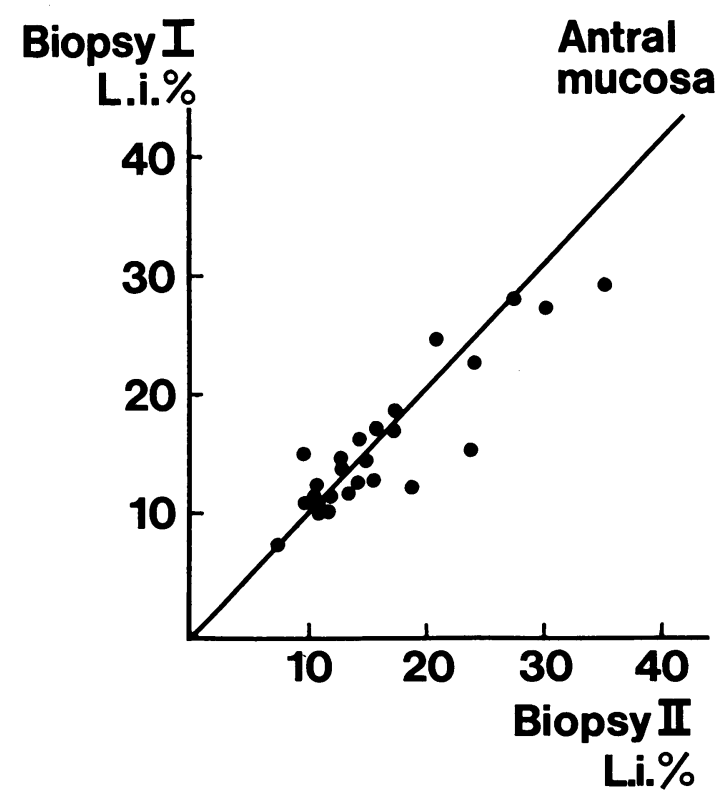

Fig 5 The correlation between labelling indices in biopsies taken near each other in the antral part of the stomach $\left(n=26, r_{S P}=0.899, \mathrm{P}<0.001\right)$. 


\begin{tabular}{|c|c|c|c|c|c|c|}
\hline \multirow[t]{2}{*}{ Endoscopic Diagnosis } & \multirow{2}{*}{$\begin{array}{l}\text { No. of } \\
\text { Patients }\end{array}$} & \multicolumn{2}{|l|}{ Antral Mucosa } & \multirow{2}{*}{$\begin{array}{l}\text { No. of } \\
\text { Patients }\end{array}$} & \multicolumn{2}{|l|}{ Fundic Mucosa } \\
\hline & & $\begin{array}{l}\text { Labelling Index } \\
\text { Estimated }\end{array}$ & Corrected & & $\begin{array}{l}\text { Labelling Index } \\
\text { Estimated }\end{array}$ & Corrected \\
\hline $\begin{array}{l}\text { Duodenal ulcer } \\
\text { Prepyloric ulcer } \\
\text { Gastric ulcer } \\
\text { Gastric cancer } \\
\text { Atrophic gastritis } \\
\text { Normal stomach }\end{array}$ & $\begin{array}{r}5 \\
4 \\
5 \\
4 \\
5 \\
10\end{array}$ & $\begin{array}{l}14.0 \pm 2.2 \\
15.5 \pm 2.2 \\
16.2 \pm 3.1 \\
16.4 \pm 4.2 \\
13.7 \pm 0.6 \\
13.9 \pm 1.6\end{array}$ & $\begin{array}{l}13 \cdot 2 \pm 2 \cdot 5 \\
14 \cdot 8 \pm 2 \cdot 4 \\
15 \cdot 5 \pm 3 \cdot 2 \\
15 \cdot 8 \pm 4 \cdot 5 \\
12.9 \pm 0.6 \\
12.8 \pm 1.8\end{array}$ & $\begin{array}{r}6 \\
4 \\
5 \\
5 \\
6 \\
10\end{array}$ & $\begin{array}{r}9.5 \pm 0.5 \\
11.8 \pm 1.2 \\
13.4 \pm 0.9 \\
20.0 \pm 4.8 \\
19.5 \pm 3.1 \\
12.1 \pm 0.6\end{array}$ & $\begin{aligned} & 8.1 \pm 0.4 \\
& 10.9 \pm 1.2 \\
& 12.5 \pm 1.1 \\
& 19.3 \pm 5.2(\mathrm{P}<0.05) \\
& 19.0 \pm 3.3(\mathrm{P}<0.05) \pm 0.7 \\
& 11.0 \pm 0.0\end{aligned}$ \\
\hline
\end{tabular}

Table Mean ( \pm SEM) estimated and corrected labelling indices in antral and fundic mucosa from patients with different gastric diseases

${ }^{1}$ The significance of differences between the labelling indices was assessed by the Mann-Whitney rank sum test.

In 33 cases the estimated labelling index in biopsies from antrum and fundus were compared (fig 6). In the three remaining patients none of the biopsies from the antrum were suitable for study. As shown, it was not possible to demonstrate any correlation between the labelling indices in the two types of gastric mucosa.

The mean estimated and corrected labelling indices in patients with different gastric diseases are noted in the table. In antral mucosa no statistically significant differences between the labelling indices were found. In fundic mucosa the lowest labelling index was found in patients with duodenal ulcer. In patients with gastric cancer or atrophic gastritis the mean

\section{Antrum}

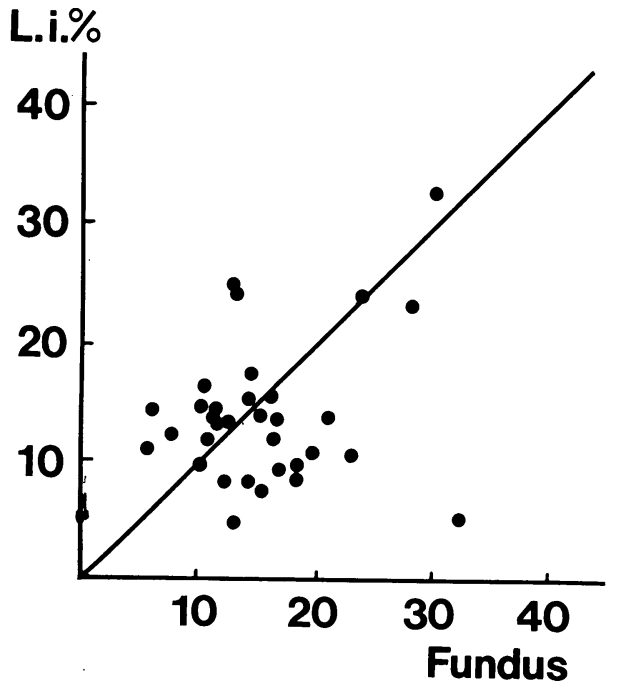

Fig 6 The correlation between labelling indices in biopsies from the antral and fundic part of the stomach $\left(n=33, r_{S P}=0.041, N S\right)$. labelling indices were significantly higher than in the other groups of patients $(\mathrm{P}<0.05)$.

\section{Discussion}

In a few severely ill patients cell proliferation in gastric mucosa has been investigated by means of autoradiography after labelling in vivo with ${ }^{3} \mathrm{H}$ thymidine (Lipkin, Sherlock, and Bell, 1966; MacDonald, Trier, and Everett, 1964). It was shown that the general pattern of epithelial renewal in the gastrointestinal tract in man is similar to that of laboratory animals. The growth pattern of human gastric mucosa is important in attempts to elucidate the pathogenesis of gastric diseases, and the need for an increased knowledge of the kinetic parameters is evident. Studies of cell proliferation in human gastric mucosa have previously been difficult to perform. We think, however, that it is possible to overcome some of the difficulties by using the method described.

Through modern fibreoptic gastroscopes many biopsies can be taken from different places in the stomach without much risk or discomfort for the patient. However, the endoscopic biopsies are small, and it is difficult to orientate the tissue correctly before the histological procedures. This means that foveolae cut longitudinally are seldom found in the specimens. In contrast to other investigators (Willems, 1972), we therefore decided to count the cells in cross sections of the foveolae. When only cross sections with at least one labelled cell are taken into consideration, only cells in the area of proliferation are included in estimations of the labelling index. It will be somewhat overestimated because those cross sections through the progenitor cell region which do not have labelled cells will not be included in the estimation of the labelling index. However, this error can be reduced by use of the nomogram (fig 2). We have found it quicker and simpler to count the cells in cross sections than in longitudinal 
sections of the gastric pits. The observer error is small and the results are highly reproducible.

In an experimental study, McDermott, Galbraith, and Dalton (1974) suggested that the duration of the S-phase of ileal epithelial cells could be prolonged considerably under certain circumstances. Similar changes in the length of the S-phase have not been demonstrated in man, but the available data are limited and further investigations are indicated. By use of double labelling techniques it should be possible to determine the duration of the S-phase in mucosal specimens incubated in vitro. In a few patients we did use double labelling with ${ }^{3} \mathrm{H}$ - and ${ }^{14} \mathrm{C}$-thymidine, but the results were disappointing since it was not possible to distinguish the cells labelled by the two isotopes. Instead we adopted the method described by Willems et al (1970). The biopsies are successively incubated in a medium containing ${ }^{3} \mathrm{H}$-thymidine at a low concentration, then for one hour in a medium without isotope, and finally in a medium with a high dose of ${ }^{3} \mathrm{H}$-thymidine. These studies are in progress, and the results will be published in due course. If the efforts to determine the duration of the S-phase $\left(\mathrm{T}_{\mathrm{S}}\right)$ succeeds, the turnover time $\left(\mathrm{T}_{\mathrm{ot}}\right)$ of the epithelial cells can be calculated from the formula: $T_{o t}=\frac{T_{s}}{L I} \times 100$. For this purpose the corrected labelling index should be used in order to obtain the most exact results.

Generally the duration of the S-phase seems to be fairly constant, and if it is assumed that it does not differ in the patients studied, the labelling index is approximately proportional to the growth rate of the cell population. Significantly higher labelling indices were found in fundic mucosa from patients with gastric cancer and atrophic gastritis than in the other groups of patients. Our observation of increased epithelial proliferation in biopsies from patients with atrophic gastritis is in accord with the results of Croft et al (1966) and of Winawer and Lipkin (1969).

The finding of no correlation between the labelling index in antral and fundic mucosa indicates that that there can be a considerable difference in the growth pattern in the two types of gastric mucosa. Valuable knowledge of cell turnover in the stomach has been obtained by measuring the cell loss from human gastric mucosa by estimation of the DNA content in gastric washings (Boyes, Crean, and Watkinson, 1971; Croft and Cotton, 1973). How- ever, the DNA rate represents the rate of loss of cells from both the antral and fundic part of the stomach. The method must therefore be inaccurate to some extent.

An important task for research workers is to discover the relevance to man of the vast amount of work which has been carried out using animals in studying cell proliferation kinetics in gastric mucosa. For this purpose the techniques of labelling endoscopic biopsies with ${ }^{3} \mathrm{H}$-thymidine in combination with autoradiography can be useful.

We are grateful to Mr N. R. Hartmann who worked out the equation for correcting the estimated labelling indices. Mr A. Hamilton rendered skilled technical assistance. This work was supported in part by Statens lægevidenskabelige forskningsråd.

References

Boyes, B. E., Crean, G. P., and Watkinson, G. (1971). Studies in the rates of epithelial cell exfoliation from the gastric mucosa in normal and in ulcer subjects. Gut, 12, 867.

Clarke, R. M. (1973). Progress in measuring epithelial turnover in the villus of the small intestine. Digestion, 8, 161-175.

Creamer, B., Shorter, R. G., and Bamforth, J. (1961). The turnover and shedding of epithelial cells. Part $I$. The turnover in the gastro-intestinal tract. Gut, 2, 110-118.

Croft, D. N., and Cotton, P. B. (1973). Gastro-intestinal cell loss in man. Digestion, 8, 144-160.

Croft, D. N., Pollock, D. J., and Coghill, N. F. (1966). Cell loss from human gastric mucosa measured by the estimation of deoxyribonucleic acid (DNA) in gastric washings. Gut, 7, 333-343.

Desai, H. G., Venugopalan, K., and Antia, F. P. (1973). Effect of red chilli powder on DNA content of gastric aspirates. Gut, 14, 974-976.

Lipkin, M. (1973). Proliferation and differentiation of gastrointestinal cells. Physiol. Rev., 53, 891-915.

Lipkin, M., Sherlock, P., and Bell, B. (1966). Cell proliferation kinetics in the gastrointestinal tract of man. II. Cell renewal in stomach, ileum, colon, and rectum. Gastroenterology, 45, 721729.

MacDonald, W. C., Trier, J. S., and Everett, N. B. (1964). Cell proliferation and migration in the stomach, duodenum, and rectum of man: radio-autographic studies. Gastroenterology, 46, 405417.

McDermott, F. T., Galbraith, A. J., and Dalton, M. K. (1974). Effects of acute renal failure on ileal epithelial cell kinetics: auto-radiographic studies in the mouse. Gastroenterology, 66, 235-239.

Max, M., and Menguy, R. (1970). Influence of adrenocorticotropin, cortisone, aspirin and phenylbutazone on the rate of exfoliation and the rate of renewal of gastric mucosal cells. Gastroenterology, 58, 329-336.

Quastler, H., and Sherman, F. G. (1959). Cell population kinetics in the intestinal epithelium of the mouse. Exp. Cell Res., 17, 420438.

Willems, G. (1972). Cell renewal in the gastric mucosa. Digestion, 6, 46-63.

Willems, G., Galand, P., and Chretien, J. (1970). Autoradiographic studies on cell population kinetics in dog gastric and rectal mucosa. Lab. Invest., 23, 635-639.

Winawer, S. J., and Lipkin, M. (1969). Cell proliferation kinetics in the gastrointestinal tract of man. Cell renewal in intestinalized gastric mucosa. J. nat. Cancer Inst., 42, 9-17. 